\title{
Stress, Meditation, and Alzheimer's Disease Prevention: Where The Evidence Stands
}

\author{
Dharma Singh Khalsa ${ }^{\mathrm{a}, \mathrm{b}, *}$ \\ 'Alzheimer's Research and Prevention Foundation, Tucson, AZ, USA \\ ${ }^{\mathrm{b}}$ Department of Internal/Integrative Medicine, University of New Mexico School of Medicine, \\ Albuquerque, NM, USA
}

Handling Associate Editor: J. Wesson Ashford

Accepted 26 May 2015

\begin{abstract}
Although meditation is believed to be over five thousand years old, scientific research on it is in its infancy. Mitigating the extensive negative biochemical effects of stress is a superficially discussed target of Alzheimer's disease (AD) prevention, yet may be critically important. This paper reviews lifestyle and stress as possible factors contributing to AD and meditation's effects on cognition and well-being for reduction of neurodegeneration and prevention of AD. This review highlights Kirtan Kriya (KK), an easy, cost effective meditation technique requiring only 12 minutes a day, which has been successfully employed to improve memory in studies of people with subjective cognitive decline, mild cognitive impairment, and highly stressed caregivers, all of whom are at increased risk for subsequent development of AD. KK has also been shown to improve sleep, decrease depression, reduce anxiety, down regulate inflammatory genes, upregulate immune system genes, improve insulin and glucose regulatory genes, and increase telomerase by $43 \%$; the largest ever recorded. KK also improves psycho-spiritual well-being or spiritual fitness, important for maintenance of cognitive function and prevention of AD. KK is easy to learn and practice by aging individuals. It is the premise of this review that meditation in general, and KK specifically, along with other modalities such as dietary modification, physical exercise, mental stimulation, and socialization, may be beneficial as part of an AD prevention program.
\end{abstract}

Keywords: Alzheimer's disease, lifestyle, meditation, memory loss improvement, prevention, stress, psychospiritual well-being, reduction of risk factors

\section{LIFESTYLE AND ALZHEIMER'S DISEASE PREVENTION}

This is a critically important time in the field of Alzheimer's disease (AD) prevention. As the search for a drug to prevent and/or cure $\mathrm{AD}$ continues to be elusive [1], low cost lifestyle measures that create high levels of brain health, stop ongoing degeneration,

\footnotetext{
${ }^{*}$ Correspondence to: Dharma Singh Khalsa, MD, Founding President and Medical Director, Alzheimer's Research and Prevention Foundation, P.O. Box 30783, Tucson, AZ 85751-0783, USA. Tel.: +1 520749 8374; Fax: +1 520838 9855; E-mail: drdharma@ alzheimersprevention.org.
}

repair neuronal damage, and prevent the type of cognitive disability that could lead to $\mathrm{AD}$, are at the forefront of the discussion of AD prevention. Emerging research suggests that lifestyle choices can make a difference, when it comes to $\mathrm{AD}$ prevention $[2,3]$. In a recent study of lifestyle modification, The Finnish Geriatric Intervention Study To Prevent Cognitive Impairment and Disability (The FINGER Study), the effects of a 2-year multi-domain intervention targeting several lifestyle and vascular risk factors were studied simultaneously. FINGER included 1,260 participants aged 60-77 years. The initial study, which ended in 2014, will continue with an extended 7 year follow up period. 
FINGER indicated that utilizing nutritional intervention, physical exercise, cognitive training, and social activities together resulted in a significant beneficial effect on overall cognitive performance. The study was the first large randomized controlled trial that suggested that it is possible to prevent cognitive decline and thus delay or prevent AD using an integrative medical program among older, at-risk individuals [4-6].

This review will initially focus on a lifestyle factor common today: chronic stress. Stress, via the cortisol connection, causes neurotoxic damage to cells in the hippocampus and elsewhere in the brain which may increase $\mathrm{AD}$ risk. Beyond that, stress has a causative association with multiple risk factors for $\mathrm{AD}$, including inflammation, calcium dysregulation, cardiovascular disease including hypertension, diabetes/insulin resistance, depression, anxiety, physical inactivity, sleep deprivation, and smoking [7,8]. A recent study of 1,796 elderly people with AD compared to 7,184 without an AD diagnosis highlighted the direct connection between anxiety, insomnia, benzodiazepine use, and AD [9]. Previously, a number of these drugs were shown to turn on AD promoting genes [10].

How meditation acts to reduce stress and cortisol levels and improve multiple aspects of health and cognition will then be reviewed. Beyond the basics of this discussion, this article will discuss research on a simple, twelve-minute, meditation technique called Kirtan Kriya (KK), that positively impacts brain and memory function, cellular health, genetic expression, and well-being. Moreover, KK may reverse memory loss in subjects with subjective cognitive decline (SCD) and mild cognitive impairment (MCI), both of which may progress to dementia [11-13].

\section{STRESS, AGING, AND NEURON DEATH}

According to leading stress researcher Robert Sapolsky Ph.D., a stressor can be defined physiologically as any perturbation from the outside world that disrupts homeostasis [14]. Beyond the physical, stress can also be psychological or emotional and the potency and pathogenicity of psychological stress cannot be ignored, as it may increase the risk of developing AD [15].

Modern stress research is considered to have begun in the last century with the work of Walter B. Cannon [16], and later recognized as the first stage of Selye's general adaptation syndrome [17]. This work led Sapolsky and others to appreciate that while acute stress actually heightens cognition, these same responses are highly deleterious when activated chronically [14].

Furthermore, aging is a time of decreased ability to handle stress and, untreated, chronic stress accelerates many of the degenerative aspects of aging, including cognitive decline. In contrast, meditation may counterbalance many aspects of the stress response and protect the brain specifically from the ravages of aging combined with stress overload [11, 18, 19].

Stress may injure hippocampal cells via the release of the hormone cortisol from the adrenal gland in response to hypothalamic and pituitary stimulatory signals, such as CRF and ACTH. Such injury could lead to dysfunction and atrophy of that critically important memory and emotional brain structure [20, 21]. Beyond that, hippocampal cellular loss is dramatically exacerbated because of the destruction of the specific neurons that control cortisol secretion from the adrenal gland [14].

This loss of feedback inhibition may lead to a persistent toxic cortisol level, thus causing the further injury or death of hippocampal cells by activating NMDA receptors, which may allow excessive extracellular calcium ion to pass through now open channels, flooding the interior of the cell with markedly excessive calcium ion. This excessive intracellular calcium leads to cytosolic injury, mitochondrial damage, severe oxidative stress, and possibly inflammation, which may ultimately lead to significant cognitive decline [22]. Current research also indicates that chronic stress arousal activates multiple inflammatory mediators, including the NF- $\mathrm{\kappa B}$ system, leading to widespread brain inflammation, especially in the hippocampus [8, 23-25]. These disturbances of central inflammation have been shown to be a hallmark of AD [26].

The negative effects of chronic stress are considerable. Beyond cognitive decline and memory loss, stress also affects numerous neurobehavioral phenomena, from anxiety to depression to various abnormal behaviors and unconscious self-defeating compulsive actions. Some of these behaviors may lead to premature cognitive decline and AD [27]. Significantly, Lupien argues that it is not simply isolated episodes of stress that do damage to the brain. Rather, it is the magnitude of cortisol exposure over the lifetime, especially middle age and beyond, that is linked to AD and promotes emotional and cognitive dysfunction, including disruption of hippocampal-dependent selective attention and explicit short term memory loss, SCD, MCI, and $\mathrm{AD}[18,28,29]$.

Further evidence links decreased memory performance and a greater risk of $\mathrm{AD}$ in people reporting 
higher levels of work-related stress, having stressprone personalities, enduring early childhood stress such as abuse, trauma, and neglect and/or suffering from midlife stress as well. In a study specific to women, for each additional stressor reported, the risk of later developing AD increased 20\% [30-33].

In a study by Wilson, those subjects who scored high in distress proneness (90th percentile) had twice the risk of developing $\mathrm{AD}$ than those in low distress proneness (10th percentile) suggesting that an increased vulnerability to psychological distress may be a risk factor for $\mathrm{AD}$.

A randomized, double blind, placebo controlled comparison of two fixed oral doses of cortisol $(40 \mathrm{mg} / \mathrm{d}$ and $160 \mathrm{mg} / \mathrm{d}$ using split doses to approximate circadian rhythm) in volunteers over four days to a matched group of healthy subjects $(n=51)$ showed reversible impaired verbal, declarative, and short term memory in those subjects receiving the higher or stress dose of cortisol [34]. Additionally, Wang showed that psychological stress in the workplace as manifest by low job control and high job strain was associated with increased risk of $\mathrm{AD}$ in late life, independent of other risk factors [35]. Chronic stress is associated with multiple brain anatomic abnormalities, including a decreased size of the anterior cingulate cortex, which leads to impaired hypothalamic-pituitary-adrenal axis regulation and perhaps an increased vulnerability to the effects of chronic stress [36].

Finally, recent stress research by Epel and Blackburn shows that stress has a pronounced negative effect on genetic health, diminishing telomerase levels, the enzyme responsible for maintenance of telomere length, the protective cap of DNA. Shorter telomeres are associated with inflammation, accelerated aging, and $\mathrm{AD}[37,38]$. Moreover, telomeres are shorter in those with childhood maltreatment $[39,40]$.

\section{MEDITATION AS ALZHEIMER'S DISEASE PREVENTION MEDICINE}

In 1949, Swiss physiologist Walter Hess, PhD, was awarded the Nobel Prize in Medicine and Physiology for his description of two centers in the hypothalamus of the cat [41]. One of the points, which he called the ergotrophic center, when stimulated electrically, produced the typical physiological features of the sympathetic stress response: rise in blood pressure, increase in pulse, faster respiratory rate, and an increase in oxygen consumption or MVO2. He broke new ground when he demonstrated an additional point in the hypothalamus that, when stimulated, caused the exact opposite of the stress response. He called it the trophotrophic center, which was associated with parasympathetic activation, relaxation, sleepiness, and withdrawal from activities. The trophotrophic system protects against stress overload and allows for recovery and regeneration [42]. This dichotomy suggests that there exists an innate, natural way to reduce the deleterious effects of stress.

Approximately twenty years later, Herbert Benson, MD, further elucidated the physiological underpinnings of the trophotrophic center. First he described what he called "The Four States": awake, sleep, dream, and the fourth state. The difference between the first three states and the fourth state is that the first three happen spontaneously, while specific actions are required to enter into the fourth state or what Benson initially called "eliciting the relaxation response (RR)" [43]:

1. Comfort: Sit easily in a chair or on the floor.

2. Quiet: Be alone in a spot where you will not be disturbed, i.e., no texts, emails, cell phones, etc., while eliciting the relaxation response.

3. Tool: Focus on a word, thought, breathing, sound, or short prayer.

4. Attitude: When other thoughts enter your mind, re-focus on your tool to the exclusion of everything else for 10 to 20 minutes twice a day.

Meditation is not blanking out your mind, for that is virtually impossible. Rather, it is a wakeful, hypo-metabolic state that is produced by following these four steps, especially the last one [43, 44]. Recently, Benson modified his original approach to two steps required to elicit the RR: Repetition of a word, sound or movement and the passive disregard of everyday thoughts when they come to mind during the practice of the chosen technique. Through four decades of research, Benson and colleagues have shown that the RR impacts genomic, structural, physical, psychological, and functional outcomes [45-52].

Other meditation techniques that have been studied prominently include the Transcendental Meditation technique (TM) as taught by Maharishi Mahesh Yogi, which uses a secret, silent, prescribed sound or mantra as its tool, and mindfulness meditation or Mindfulness Based Stress Reduction (MBSR), a Buddhist approach with the focus on the breath as its tool. 


\section{TO REVIEW}

1. RR: The person selects their own tool. Time depends on technique but generally may be for 20 minutes twice a day.

2. TM: A personalized silent sound is prescribed. 20 minutes twice a day.

3. MBSR: The focus is on the breath for up to 40 minutes at a time.

Following a discussion of the research surrounding these meditation techniques, KK, as taught by Yogi Bhajan, $\mathrm{PhD}$, Master of Kundalini and White Tantric Yoga, will be reviewed. KK has unique characteristics that make it precise in its actions. Beyond that, KK takes only one 12-minute session a day to create its multiple salubrious benefits.

\section{$R R$}

Elicitation of the RR, regardless of the technique used, has been proven to have multiple general and cognitive health benefits from decreasing hypertension, and improving heart disease, to maximizing gene expression including the upregulation of insulin pathway genes, which could help prevent dementia, as insulin resistance may be risk factor for $\mathrm{AD}[19,44-47$, 53-55].

In Bhasin's 8-week genomic study of 19 long-term RR practitioners, 19 healthy controls, and 20 new meditators, the molecular mechanisms underlying RRinduced physiological changes were elucidated and shown to induce gene expression differences that are the opposite to transcriptional alterations induced by chronic stress. RR practice enhanced gene expression associated with energy metabolism and mitochondrial function, thus improving mitochondrial energy production and resiliency. The significance of this work lies in the fact that mitochondrial energy dysfunction has also been postulated to be an associated causative factor of $\mathrm{AD}$ development [56].

\section{$T M$}

In contrast to stress, meditation studies, starting with $\mathrm{TM}$, have been shown to lower cortisol levels $[57,58]$. Moreover, the TM program has been shown to have multiple benefits, not unlike the RR mentioned above. In a landmark study, it was shown that as a group, longterm TM program participants were physiologically 12 years younger than their chronological age [59].
More than 350 peer-reviewed research studies on the TM technique have been published in over 160 scientific journals. In recent research, there was a $48 \%$ reduction in heart disease deaths in people practicing TM; further studies confirmed its effect on hypertension, and a heightened reduction of anxiety [60]. Reducing these risk factors may help in the prevention of dementia and AD. TM has also been shown to improve brain functioning and stress reactivity in college students, as well as improve psychological functioning [61]. To date, no TM studies have been conducted with patients diagnosed with SCD, MCI, or AD.

\section{$M B S R$}

Mindfulness meditation is said to involve the development of awareness of present-moment experience with a compassionate, non-judgmental stance [62].

MBSR training consists of eight group meetings lasting two and a half hours each, plus one full day (6.5 hours) during the sixth week of the course. The training also incorporates a visualized body scan, where the practitioner tries to identify areas of physical stress, and easy stretching, and meditation. MBSR typically begins with awareness of breathing, and then evolves to include the perception of different sensations, such as sound, sight, taste, thoughts, and emotions [62, 63]. Participants also receive audio recordings containing 45 minutes of guided mindfulness exercises to practice at home. Although 40 minutes per day are typically required, in one study the time of subject participation averaged 27 minutes a day. This particular study showed changes in brain structure, especially the hippocampus [63]. MBSR has also been shown to impact sleep, mood, stress, and fatigue [64].

A MBSR pilot study in 14 subjects with MCI showed interesting results in regards to the prevention of advancement to dementia. While imaging studies were positive, showing reduced hippocampal atrophy among adults with MCI and increased functional connectivity between the posterior cingulate cortex and bilateral medial prefrontal cortex, memory tests were inconclusive. The subjects meditated for 30 minutes a day and also utilized the other aspects of MBSR mentioned above [65].

In a MBSR research study called "Shamatha Project", 30 subjects practiced mindfulness meditation for 6 hours a day for three months in a retreat setting and were compared to 30 matched wait-list controls. The results showed an increase in the DNA-protecting enzyme telomerase. Measurements of salivary cortisol, 
however, were unchanged [66]. The results were also positive for focused attention, depression, anxiety, and psychological well-being [67]. This study was conducted in people with no memory complaints.

In a recent MBSR study, Paller showed that there was benefit for patients with cognitive decline and their caregivers in a project involving 37 subjects: 17 patients and 20 caregivers. Post-study analysis indicated increased quality of life ratings, fewer depressive symptoms, and better subjective sleep quality. The findings regarding cognition were not significant [68]. In comparison, studies utilizing KK have shown improved Mini-Mental Status Examination and Trail Making B scores in stressed dementia caregivers [69].

The effects of MBSR on cognition and emotion without memory concerns in community-based older adults are reviewed extensively by Kaszniak [70].

\section{KK MEDITATION}

In addition to the four steps described above, KK, utilizes the following five specific actions:

1. Breath: In KK, the breath is allowed to come naturally.

2. Posture: One can sit comfortably in a chair or on the floor.

3. Sound: KK prescribes very specific sounds.

4. Hand position and finger movements: KK uses a specific finger tip movement sequence.

5. Focus of concentration: KK utilizes a unique focus.

KK can be performed by those of any age with memory loss and various degrees of impairment, with appropriate supervision. Moreover, the benefits accrue from the very first practice session [71, 72]. Most
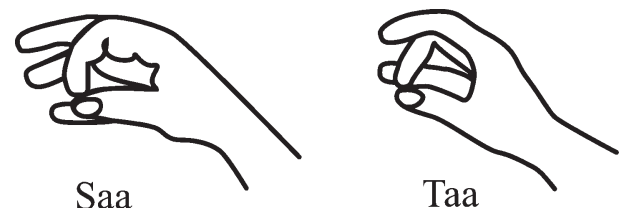

significantly, it takes only one 12-minute session a day using a recording to obtain the benefits of $\mathrm{KK}$ and requires no other training sessions, seminars, retreats, additional practices, or costs.

$\mathrm{KK}$ is a multifaceted, multisensory exercise that engages and activates conscious awareness. It increases cerebral blood flow to important anatomical brain areas and, as discussed below, has numerous other benefits, both in caregivers and those with cognitive decline [69, 71-74].

\section{Posture}

The practitioner can sit comfortably in a chair with their feet flat on the floor. The essence of the posture is to be comfortable and sit with the spine straight with only the natural curvature.

\section{Breath}

The person simply breathes naturally as the meditation unfolds.

Eyes

Eyes are closed.

The sounds

KK uses the sounds, Saa, Taa, Naa, Maa. The tune to which these sounds are sung is the first four notes of the familiar children's song, "Mary had a Little Lamb." That is, the notes are "Mar-y had a." See Fig. 1. The jaw should remain relaxed as you sing.
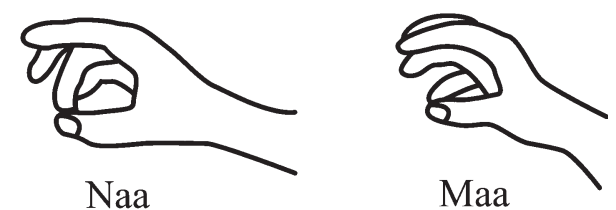

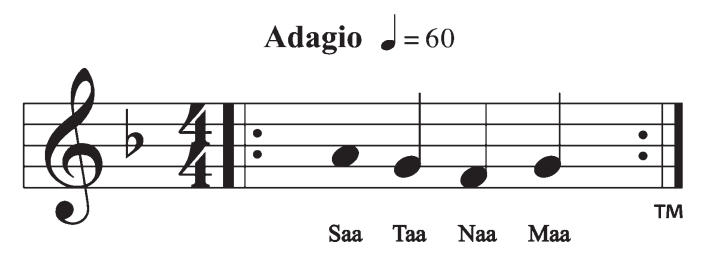

Fig. 1. KK: Finger movement and music. 


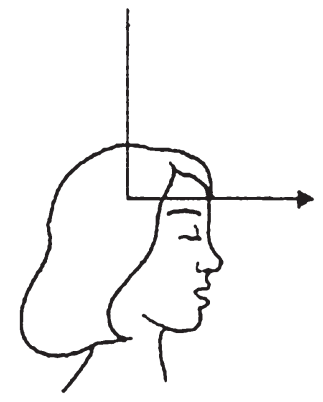

Fig. 2. L Form of concentration.

\section{The finger movement}

With the hands on the knees, the thumb is touched to each of the other four fingers in sequence. Both hands perform the same movements simultaneously. Figure 1 illustrates: On Saa, touch the index fingers of each hand to the thumbs; On Taa, touch the middle fingers to the thumbs; On Naa, touch the ring fingers to the thumbs; On Maa, touch the little fingers to the thumbs.

The sequence is always forward: thumb to index finger, middle finger, ring finger, and pinky; never backwards.

\section{The visualization}

The sound is visualized coming down from the top of the head, and out the middle of the forehead in the center, lined up with the nose like a capital letter "L". One may think of this action as sweeping through like a broom. See Fig. 2.

\section{The sequence}

The sounds Saa Taa Naa Maa are utilized while also performing the movements with the fingers of both hands. At the same time, the sound is visualized flowing in through the top of the head and out the middle of the forehead in an L shape.

When outside thoughts intrude, simply return your focus to the sounds and visualization.

1. For two minutes, sing out loud.

2. For the next two minutes, sing in a stage whisper.

3. For the next four minutes, say the sound silently to yourself.

4. Then whisper the sound for two minutes

5. Complete the sequence by singing out loud for the last two minutes.
This will complete the 12-minute meditation. A digital clock, timer, or watch can be used to time the exercise, rather than an alarm.

To come out of the exercise, inhale very deeply through the nose, stretch your hands above your head, and then bring them down slowly in a sweeping motion as you exhale through the nose. Take a couple of deep nasal breaths before opening your eyes and resuming activity.

\section{EFFECTS OF KK ON BRAIN AND COGNITION}

$\mathrm{KK}$ is an active meditation and there are several mechanisms by which it may work. Practicing it may stabilize brain synapses by increasing important neurotransmitters, such as acetylcholine, norepinephrine, glutamate, and possibly GABA as well [75-77]. This is significant, as previous research suggests that synaptic dysfunction is a unique hallmark of AD. Compelling data supports the hypothesis that synaptic changes play a key role in its pathogenesis, probably contributing directly to the profound cognitive impairment that is characteristic of the disease [78, 79].

According to the cortical homunculus, a representation of anatomical divisions of the motor-sensory cortex, the tongue, vocal apparatus, and the dense nerve endings in the fingertips are associated with a high degree of representation [73].

Therefore, when the practitioner utilizes the fingertips in conjunction with the sound, specific areas in the brain, as seen on SPECT scans, are activated. Khalsa and Newberg showed significant cerebral blood flow changes during the practice of KK $[71,80]$. Such activation of the brain with increased blood flow may have a beneficial effect or provide protection against neurodegeneration [81].

As shown in Fig. 3, the frontal lobes exhibited increased cerebral blood flow [80].

As seen in Fig. 4, the posterior cingulate gyrus (PCG) is also activated [80]. This is relevant because the PCG is highly connected to other important anatomical areas and one of the most metabolically active regions in the brain, and it is critically important for many types of memory and emotional functions [82]. Reduced cerebral blood flow and hypometabolism in the PCG are early signs of AD and are frequently present before a clinical diagnosis is evident, indicating a particular vulnerability of this structure to neurodegeneration. Moreover, in early AD, the connection between the PCG and the hippocampus 


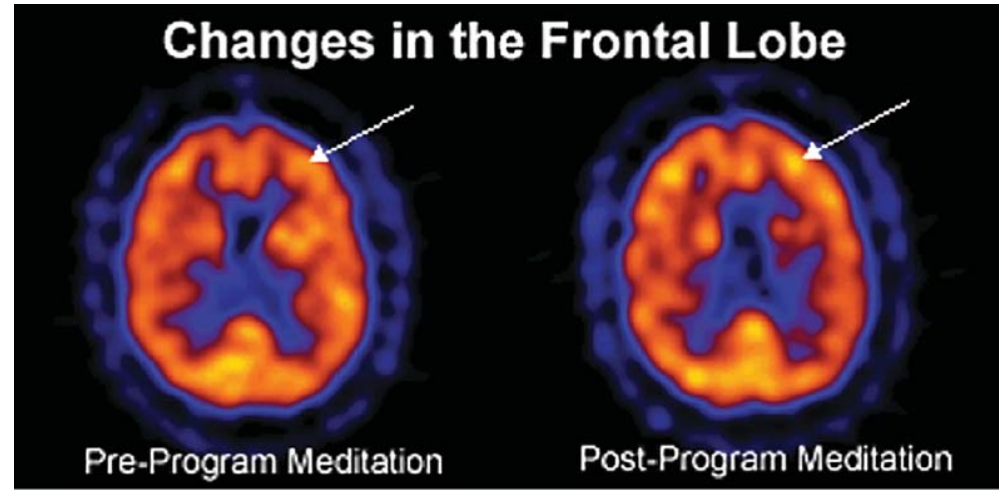

Fig. 3. Changes in the frontal lobe.

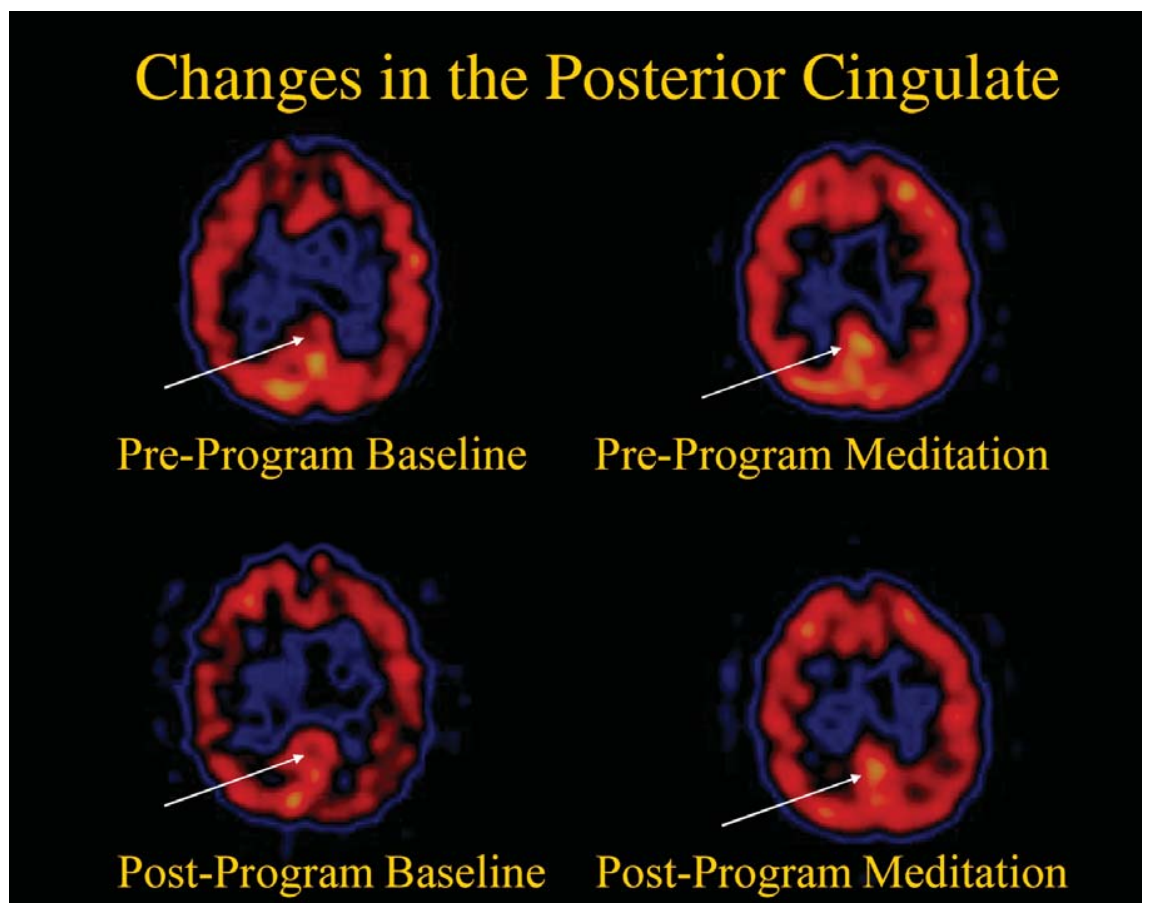

Fig. 4. Changes in the posterior cingulate gyrus.

is disrupted [82]. Perhaps it is reasonable to consider, therefore, that regular activation of the PCG may lead to a decreased risk for $\mathrm{AD}$ over time.

Shown in Fig. 5 is the before and after picture of a subject's brain on KK [80]. The brain on the left is smaller and has dimples in the top part of the brain. These dimples signify a lack of blood flow. The after scan shows a symmetrical brain with increased blood flow, potentially representing an improvement of function.

In the first study in which meditation was explored in subjects with memory impairment, Newberg [71] described positive effects of KK on cognitive function and cerebral blood flow. The experimental group practiced KK for 12 minutes per day while the comparison group listened to music for an equal amount of time. The 15 experimental participants ranged in age from 52 to 77 (mean 64, s.d. 8). Seven had SCD, five had MCI, and three had AD. However, one of those with $\mathrm{AD}$ was found to be incapable of following the directions for performing KK and this data was not included further in the results. Thus, 14 participants constituted the final experimentation group, two of whom had AD. 


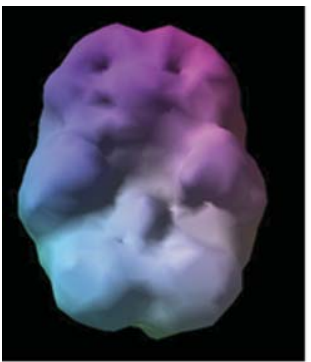

Before

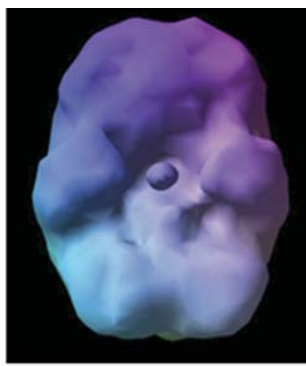

After
Kirtan Kriya

Fig. 5. Enhanced cerebral blood flow.

The experimental group participants were scanned and then individually instructed in how to perform KK meditation. The participants then performed KK for a 12-minute period while supervised by a researcher and were re-scanned. They were given a CD of the technique and told to practice it 12 minutes daily for eight weeks at home.

The comparison group comprised three subjects with SCD and two with MCI, ranging from 56 to 79 years old (mean 65, s.d.10). They listened daily to a 12-minute long CD containing two Mozart violin concertos.

After 8-weeks of at-home practice, participants were re-scanned both before and after practicing KK. They were also given a battery of neuropsychological tests. The testing demonstrated a significant improvement in scores on a verbal fluency test, Animal Naming, and a test of divided attention, Trail Making, Part B. Subjectively, the experimental participants also reported improvement in their overall memory functioning. This is important, given Reisberg's findings that people with SCD are at higher risk for progression to MCI and later $\mathrm{AD}$ [12].

As can be seen in the scans below in Fig. 6, from Newberg [71, 72], KK practice produced a difference in activation in the prefrontal cortex, the frontal lobe (also seen above in Fig. 3), and the anterior cingulate gyrus, both the first time the subjects practiced it and, more prominently, after eight weeks of doing KK 12 minutes a day.

As MacLullich's [36] finding on the association between the anterior cingulate cortex and stress regulation demonstrates, this increased activity may improve hypothalamic-pituitary-adrenal axis function. Of interest is that the recent Super Ager study revealed that the oldest old who maintained optimal memory function had a larger anterior cingulate gyrus and cerebral cortex; these same two findings were seen in people

\section{Changes in the Anterior Cingulate Gyrus}
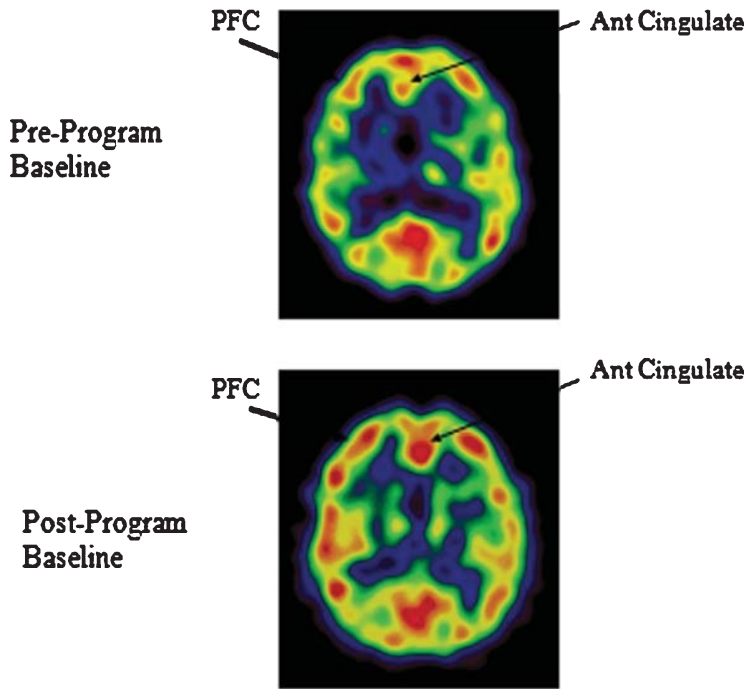

Fig. 6. Enhanced cerebral blood flow in the prefrontal cortex (PFC) and anterior cingulate gyrus.

who practiced KK $[71,72,83]$. Finally, the enhancement of the prefrontal cortex is especially important because the diminished prefrontal cortex activity is associated with MCI [71, 72].

Beyond the scanning results, utilizing the POMS test, it was shown that KK boosted mood, energy, and emotional well-being in those subjects with memory loss $[69,71,72]$. This is important because, as discussed above, other meditation techniques require extensive training and long meditation periods to produce the same effects.

\section{ADDITIONAL BENEFITS OF KK}

Beyond the above studies, additional research on KK demonstrates a diminished loss of brain volume with age $[71,72]$, which is consistent with other observations on meditation [84]. Additionally, in a study of 37 stressed family dementia caregivers, the effects of KK on mental health, cognition, and immune cell telomerase activity were examined. The experimental group practiced KK for 12 minutes a day for 8 weeks while the control group listened to relaxation music [69]. The outcome revealed that the KK group had significantly lower levels of depressive symptoms, and greater improvement of mental health, well-being, and memory, compared with the control group. Moreover, the KK group showed a $43 \%$ improvement in 
telomerase activity, the largest ever reported, compared with $3.7 \%$ in the relaxation group. These findings suggest an improvement in stress-induced cellular aging.

This study also demonstrates positive epigenetic effects with an upregulation of 19 genes related to positive immune function and a down regulation of 49 genes associated with inflammation, such as proinflammatory cytokines [85], potentially indicating lower AD risk. Additionally, 9 of the subjects were randomized to receive FDG-Pet Scans at baseline and post-intervention, and the analysis of the results from these scans confirms that KK activates the whole brain including the occipital cortex [86].

Finally, KK improves sleep. This is important because poor sleep hygiene is a risk factor for $\mathrm{AD}$ [87]. A recent study showed that AD patients and their caregivers who practiced KK reported less stress and better sleep. This study also reports improved psychological well -being with KK [8, 23].

\section{SPIRITUAL FITNESS: THE NEW DIMENSION IN AD PREVENTION}

A well-known and vitally important benefit of meditation is the cultivation of higher levels of psychospiritual well-being. Acceptance, independence, and socialization, as well as discovering meaning and purpose in life, all part of spiritual fitness, may reduce risk for the development of MCI and AD [88, 89]. Additionally, one of the above mentioned aspects of spiritual fitness, having meaning in life, has been shown to reduce AD risk by itself [90]. Higher levels of psychological well-being also increase telomere length and are inversely associated with amyloid plaques and tau tangles deposition in the posterior cingulate gyrus [91]. Moreover, in preliminary studies, having a sense of spirituality, regardless of its origin, reduces risk and slows AD progression [92]. This heightened level of consciousness and cognition is an important frontier in $\mathrm{AD}$ prevention, and a dimension that should be pursued further.

\section{CONCLUSION}

The brain appears to respond favorably to regular meditation practice. Although meditation is believed to be over five thousand years old, scientific research on it is in its infancy. Mitigating the extensive negative biochemical effects of stress is a rarely discussed target of $\mathrm{AD}$ prevention and treatment. This paper reviews lifestyle and $\mathrm{AD}$ prevention, stress, and neurodegeneration, and meditation's striking effects on cognition and well-being. It discusses multiple forms of meditation and highlights KK, which has been successfully employed in studies of people with SCD and MCI, as well as highly stressed caregivers. Research suggests that KK enhances memory and reduces $\mathrm{AD}$ risk by improving sleep, decreasing depression, increasing well-being, down regulating inflammatory genes, upregulating immune system genes, improving insulin and glucose metabolism, and increasing telomerase by $43 \%$; the largest ever recorded. Moreover, Newberg discovered objective evidence of memory loss reversal when studying KK [71, 72]. KK also improves a number of aspects of mental health; all important for maintenance of cognitive function [93]. KK, therefore, reduces multiple risk factors for $\mathrm{AD}$ [94].

Most noteworthy is the fact that $\mathrm{KK}$ is a self-directed training program using a $\mathrm{CD}$ with the amount of time necessary being only 12 minutes a day for these results to be observable. Based on these studies, KK is a safe, affordable, easy to learn in all age groups, fast acting, and side-effect free meditation exercise that should be considered for inclusion as part of an AD prevention program, right alongside other potentially beneficial modalities such as diet, exercise, mental stimulation, and social activity. KK may also be utilized as a standalone therapy in those for whom a complete lifestyle modification program is impractical. Finally, KK can theoretically be combined with pharmacological therapy, thereby possibly increasing the drug's preventive or therapeutic benefit. Further studies are ongoing and results and observations including memory, sleep, mood, well-being, and stress, are being tested in larger studies on subjects with SCD and MCI.

\section{Human and animals experimentation guidelines}

Compliance with guidelines on human experimentation as well as protocol approval by a local Institutional Review Board was obtained in all the research cited in this review. No animals were utilized.

\section{ACKNOWLEDGMENTS}

This is a review article, and the financial support for the research done is mentioned in each referenced article. The author is the President and Medical Director of the Alzheimer's Research and Prevention Foundation, which helped support research on KK.

The author's disclosures available online (http:// j-alz.com/manuscript-disclosures/14-2766r4). 


\section{REFERENCES}

[1] Carrillo MC, Thies W, Bain L (2012) The global impact of Alzheimer's disease. In Advances in Biological Psychiatry, Vol. 28, Alzheimer's Disease-Modernizing Concept, Biological Diagnosis and Therapy; Adv Biol Psychiatry, Hampel $\mathrm{H}$, Carillo MC, eds. Karger, Basel, pp. 1-14.

[2] Christensen K, Thinggaard M, Oksuzyan A, Steenstrup T, Andersen-Ranberg K, Juene B, McGue M, Vaupel JW, McGue M, Vaupel JW (2013) Physical and cognitive functioning of people older than 90 years: A comparison of 2 Danish cohorts born 10 years apart. Lancet 382, 1507-1513.

[3] Matthews FE, Arthur A, Barnes LE, Bond J, Jagger C, Robinson L, Brayne C; Medical Research Council Cognitive Function and Ageing Collaboration (2013) A two-decade comparison of prevalence of dementia in individuals aged 65 years and older from three geographical areas of England: Results of the Cognitive Function and Ageing Study 1 and 11. Lancet 382, 1405-1412.

[4] Kivipelto M, Solomon A, Ahtiluoto S, Ngandu T, Lehtisalo J. Antikainen R, Lars Bäckman L, Hänninen T, Jula A, Laatikainen T, Lindström J, Mangialasche F, Nissinen A, Paajanen T, Pajala S, Peltonen M, Rauramaa R, StigsdotterNeely A, Strandberg T, Tuomilehto J, Soininen H (2013) The Finnish geriatric intervention study to prevent cognitive impairment and disability (FINGER): Study design and progress. Alzheimers Dement 9, 657-665.

[5] Imtiaz B, Tolppanen A, Kivipelto M, Soininen H (2014) Future directions in Alzheimer's disease from risk factors to prevention. Biochem Pharmacol 88, 661-670.

[6] Ngandu T, Lehtisalo J, Solomon A, Levälahti E, Ahtiluoto S, Antikainen R, Bäckman L, Hänninen T, Jula A, Laatikainen $\mathrm{T}$, Lindström J, Mangialasche F, Paajanen T, Pajala S, Peltonen M, Rauramaa R, Stigsdotter-Neely A, Strandberg T, Tuomilehto J, Soininen H, Kivipelto M (2015) A 2 year multidomain intervention of diet, exercise, cognitive training, and vascular risk monitoring versus control to prevent cognitive decline in at-risk elderly people (FINGER): A randomized controlled trial. Lancet 385, 2255-2263.

[7] Barnes DE, Yaffe K (2011) The projected effect of risk factor reduction on Alzheimer's disease prevalence. Lancet Neurol 10, $819-825$.

[8] Innes KE, Selfe TK, Brown C, Rose KM, ThompsonHeisterman A (2012) The effects of meditation on perceived stress and related indices of psychological status and sympathetic activation in persons with Alzheimer's disease and their caregivers: A pilot study. Evid Based Complement Altern Med 2012, 927509

[9] De Gage S, Moride Y, Ducruet T, Kurth K, Verdoux H, Tournier M, Pariente A, Begaud B (2014) Benzodiazepine use and risk of Alzheimer's disease: Case-control study. BMJ 349, g5205.

[10] Lauterbach EC (2012) Psychotropic drug effects on gene transcriptomics relevant to Alzheimer's disease. Alzheimers Dis Assoc Disord 26, 1-7.

[11] Newberg AB, Wintering N, Khalsa DS, Roggenkamp $\mathrm{H}$, Waldman RW (2010) Meditation effects on cognitive function and cerebral blood flow in subjects with memory loss: A preliminary study. $J$ Alzheimers Disease 20, 517-526.

[12] Reisberg B, Shulman MB, Torossian C, Leng L, Zhu W (2010) Outcome over seven years of healthy adults with and without subjective cognitive impairment. Alzheimers Dement 6, $11-24$
[13] Boyle PA, Wilson RS, Aggarwai NT, Tang Y, Bennett DA (2006) Mild cognitive impairment: Risk of Alzheimer's disease and rate of cognitive decline. Neurology 67, 441-445.

[14] Sapolsky R (1992) Stress, the Aging Brain and the Mechanisms of Neuron Death, Bradford, Cambridge.

[15] Wilson RS, Arnold SE, Schneider JA, Kelly JF, Tang Y, Bennett DA (2006) Chronic psychological distress and risk of Alzheimer's disease in old age. Neuroepidemiology 27, 143-153.

[16] Cannon WB (1914) The emergency function of the adrenal medulla in pain and the major emotions. Am J Physiol 33, 356-372.

[17] Selye H (1959) Perspectives in stress research. Perspect Biol Med 2, 403-416.

[18] Lupien SJ, McEwen BS, Gunnar MR, Heim C (2009) Effects of stress throughout the lifespan on the brain, behavior and cognition. Natl Rev Neurosci 10, 434-445.

[19] Benson H, Beary JF, Carol MP (1974) The relaxation response. Psychiatry 37, 37-46.

[20] Stein-Behrins BA, Sapolsky R (1992) Stress, glucocorticoids and aging. Aging Clin Exp Res 4, 197-210.

[21] McEwen B, Sapolsky RA (1992) Stress and cognitive function. Endocrine Rev 7, 284-301.

[22] Armanini MP, Hutchins C, Stein BA, Sapolsky RM (1990) Glucocorticoid endangerment of hippocampal neurons is NMDA-receptor dependent. Brain Res 532, 7-12.

[23] Innes KE, Selfe TK (2014) Meditation as a therapeutic intervention for adults at risk for Alzheimer's disease - potential benefits and underlying mechanisms. Front Psychiatry 5, 40.

[24] Bredesen D (2014) Reversal of cognitive decline: A novel therapeutic program. Aging 6, 707-717.

[25] McEwen B (1998) Protective and damaging effects of stress mediators. $N$ Engl J Med 338, 171-179.

[26] Zhang G, Li J, Purkayastha S, Tang Y, Zhang H, Yin Y, Li B, Liu G, Cai D (2013) Hypothalamic programming of systemic ageing involving IKK-b, NF-kB and GnRH. Nature 497, 211-216.

[27] Hellhammer DH (2008) Neurobehavioral medicine and stress-related disorders in stress. In The Brain-Body Connection. Key Issues in Mental Health, Hellhammer DH, Hellhammer J, eds. Karger, Basel, vol 174, pp. 1-10.

[28] Lupien S, Lecours AR, Lussier I, Schwartz G, Nair NPV, Meaney MJ (1994) Basal cortisol levels and cognitive deficits in human aging. J Neurosci 14, 2893-2903.

[29] Lupien S, de Leon M, de Santi S, Convit A, Tarshish C, Nair NPV, Thakur M, McEwen BS, Hauger RL, Meaney MJ (1998) Cortisol levels during human aging predict hippocampal atrophy and memory deficits. Nat Neurosci 1, 69-73, 329.

[30] Wilson RS, Begeny CT, Boyle PA, Schneider JA, Bennett DA (2011) Vulnerability to stress, anxiety, and development of dementia in old age. Am J Geriatr Psychiatry 19, 327-334.

[31] Peavy GM, Lange KL, Salmon DP, Patterson TL, Goldman S, Gamst AC, Mills PJ, Khandrika S, Galasko D (2007) The effects of prolonged stress and APOE genotype on memory and cortisol in older adults. Biol Psychiatry 62, 472-478.

[32] Bornstein AR, Copenhaver CI, Mortimer JA (2006) Earlylife risk factors for Alzheimer disease. Alzheimer Dis Assoc Disord 20, 63-72.

[33] Heim C, Newport DJ, Miller AH, Nemeroff CB (2000) Long term neuroendocrine effect of childhood maltreatment. JAMA 284, 2321. 
[34] Newcomer JW, Selke G, Melson AK, Hershey T, Craft S, Richards K, Alderson AL (1999) Decreased memory performance in healthy humans induced by stress-level cortisol treatment. Arch Gen Psychiatry 56, 527-533.

[35] Wang HX, Wahlberg M, Karp A, Winblad B, Fratiglioni L (2012) Psychological stress at work is associated with increased dementia risk in late life. Alzheimers Dementia 8, 114-120.

[36] MacLullich AM, Ferguson KJ, Wardlaw JM, Starr JM, Deary IJ, Seckl JR (2006) Smaller left anterior cingulate cortex volumes are associated with impaired hypothalamicpituitary-adrenal axis regulation in healthy elderly men. J Clin Endocrinol Metab 91, 1591-1594.

[37] Epel ES, Lin J, Dhabhar FS, Wolkowitz OM, Putermann E, Karan L, Blackburn EH (2010) Dynamics of telomerase activity in response to acute psychological stress. Brain Behav Immun 24, 531-539.

[38] Lukens JN, Van Deerlin V, Clark CM, Xie SX, Johnson FB (2009) Comparisons of telomere length in peripheral blood and cerebellum in Alzheimer's disease. Alzheimers Dement 5, 463-469.

[39] Tyrka AR, Price LH, Kao HT, Porton B, Marsella SA, Carpenter LL (2010) Childhood maltreatment and telomere shortening: Preliminary support for an effect of early stress on cellular aging. Biol Psychiatry 67, 531-534.

[40] Price LH, Kao HT, Burgers DE, Carpenter LL, Tyrka AR (2013) Telomeres and early-life stress: An overview. Biol Psychiatry 73, 15-23.

[41] Hess WR (1925) Ueber die Wechselbeziehungen Zwischen Psychischen und Vegetativen Funktionen. Schweiz Arch Neurol Psychiatr 16, 36-55.

[42] Hellhammer DH (2008) Neurobehavioral medicine and stress-related disorders. In Stress: The Brain-Body Connection. Key Issues in Mental Health, Hellhammer DH, Hellhammer J, eds. Karger, Basel, vol 174, pp. 21-38.

[43] Benson H, Beary JF, Carol MP (1974) The relaxation response. Psychiatry 37, 37-46.

[44] Benson H (1975) The Relaxation Response, Morrow, New York

[45] Dusek JA, Hibberd PL, Buczynski B, Chang BH, Dusek KC, Johnston JM, Wohlhueter AL, Benson H, Zusman RM (2008) Stress management vs lifestyle modifications on systolic hypertension and medication elimination: A randomized trial. J Alter Complement Med 14, 129-138.

[46] Dusek JA, Out HH, Wohlhueter AL, Bhasin M, Zerbinin LF, Joseph MG (2008) Genomic counter-stress changes induced by the relaxation response. PLoS One 3, e2576.

[47] Bhasin MK, Dusek JA, Chang BH, Joseph MG, Denninger JW, Fricchione GL, Benson H, Liebermann TA (2013) Relaxation response induces temporal transcriptome changes in energy metabolism, insulin secretion, and inflammatory pathways. PLoS One $\mathbf{8}$, e62817.

[48] Lazar SW, Bush G, Gollub RL, Fricchione GL (2000) Functional brain mapping of the relaxation response and meditation. Neuroreport 11, 1581-1585.

[49] Lazar SW, Kerr CE, Wasserman RH, Gray JR, Greve DN Treadway MT (2005) Meditation experience is associated with increased cortical thickness. Neuroreport 16, 1893-1897.

[50] Mandle CL, Jacobs SC, Arcari PM, Domar AD (1996) The efficiency of relaxation response interventions with adult patients: A review of the literature. $J$ Cardiovasc Nurs $\mathbf{1 0}$, 4-26.

[51] Jacobs GD (2001) Clinical applications of the relaxation response and mind-body interventions. J Altern Complement Med 7(Suppl 1), S93-S164.
[52] Samuelson M, Foret M, Baim M, Lerner J, Fricchione G, Benson H, Dusek J, Yeung A (2010) Exploring the effectiveness of a comprehensive mind-body intervention for medical symptom relief. J Altern Complement Med 16, 187-192.

[53] Biessels GJ, Kappelle LJ (2005) Diabetic Encephalopathy Study Group. Increased risk of Alzheimer's disease in type II diabetes: Insulin resistance of the brain or insulin-induced amyloid pathology? Biochem Soc Trans 33, 1041-1044.

[54] Dusek JA, Chang BH, Zaki J, Lazar S, Deikin A, Stefano GB, Wohlhueter AL, Hibberd PL, Benson H (2006) Association between oxygen consumption and nitric oxide production during the relaxation response. Med Sci Monit 12, CR1-CR10.

[55] Puustinen PJ, Koponen H, Kautianen H, Mantyselka P, Vanhala M (2011) Psychological distress predicts the development of metabolic syndrome: A prospective population based study. Psychom Med 73, 158-165.

[56] De la Monte SM, Tong M (2014) Brain metabolic dysfunction at the core of Alzheimer's disease. Biochem Pharmacol 88, 548-559.

[57] MacClean CRK, Walton K, Wenneberg S, Levitsky DK, Mandarino J, Waziri R, Hillis S, Schnieder, R (1997) Effects of transcendental meditation program on adaptive mechanisms: Changes in Hormone levels and responses to stress after 4 months of practice. Psychoneuroendocrinology 22, 277-295.

[58] Alexander C, Langer EL, Newman R, Chandler H, Davies J (1989) Transcendental meditation, mindfulness, and longevity: An experimental study with the elderly. J Personality Social Psychol 57, 950-964.

[59] Jevining R (1978) The transcendental meditation technique, adrenal cortical activity and implications for stress. Experientia 34, 618-619.

[60] Orme-Johnson D, Barnes VA, Schneider RH (2011) Effects of the transcendental meditation program on cardiovascular risk factors and clinical events. In Heart and Mind: The Practice of Cardiac Psychology 2nd ed, Allan R, Fisher J, eds, American Psychological Association, Washington, DC.

[61] Travis F, Haaga DAF, Hagelin J, Tanner M, Nidich S, Gaylord-King C, Grosswald S, Rainforth M, Schneider R (2009) Effects of transcendental meditation practice on brain functioning and stress reactivity in college students. Int J Psychophysiol 71, 170-176.

[62] Kabat-Zinn J (1990) Full catastrophe living: Using the wisdom of your body and mind to face stress, pain and illness, Delacorte, New York.

[63] Hotzel B, Carmody J, Vangel M, Congleton C, Yerramsetti SM, Gard T, Lazar S (2011) Mindfulness practice leads to increases in regional brain matter density. Psychiatry Res 191, 36-43.

[64] Carlson LE, Garland SN (2005) Impact of mindfulnessbased stress reduction (MBSR) on sleep, mood, stress and fatigue symptoms in cancer outpatients. Int J Behav Med 12, 278-285.

[65] Wells RE, Kerr CE, Wolkin J, Dossett M, Davis RB, Walsh J, Wall R, Kong J, Kaptchuk T, Press D, Phillips RS, Yeh G (2013) Meditation for Adults with Mild Cognitive Impairment: A Pilot Randomized Trial. J Am Geriatr Soc 61, 642-645.

[66] Jacobs TL, Epel ES, Lin J, Blackburn EH, Wolkowitz OM, Bridwell DA, Zanesco AP, Aichele SR, Sahdra BK, MacLean KA, King BG, Shaver PR, Rosenberg EL, Ferrer E, Wallace BA, Saron CD (2011) Intensive meditation training, immune cell telomerase activity, and psychological mediators. Psychoneuroendocrinology 36, 664-681.

[67] MacClean KL, Ferrer E, Aichele SR, Bridwell DA, Zanexco AP, Jacobs TL (2010) Intensive meditation training improves 
perceptual discrimination and sustained attention. Psychol Sci 21, 829-839.

[68] Paller KA, Creery JD, Florczak SM, Weintraub S, Mesulam MM, Reber PJ, Kiragu J, Rooks J, Safron A, Morhardt D, O'Hara M, Gigler KL, Molony JM, Maslar M (2014) Benefits of mindfulness training for patients with progressive cognitive decline and their caregivers. Am J Alzheimers Dis Other Demen 30, 257-267.

[69] Lavretsky H, Epel ED, Siddarth P, Nazarian N, St Cyr N, Khalsa DS, Lin J, Blackburn E, Irwin MR (2012) A pilot study of yogic meditation for family dementia caregivers with depressive symptoms: Effects on mental health, cognition, and telomerase activity. Int J Geriatr Psychiatry 28, 57-65.

[70] Kaszniak AW (2011) Meditation, mindfulness, cognition, and emotion: Implications for community-based older adults programs. In Enhancing Cognitive Fitness In Adults: A Guide to The Use And Development of Community-Based Programs, Hartman-Stein PE, La Rue A, eds. Springer Science \& Business Media, LLC, New York, pp. 85-104.

[71] Newberg AB, Wintering N, Khalsa DS, Roggenkamp H, Waldman RW (2010) Meditation effects on cognitive function and cerebral blood flow in subjects with memory loss: A preliminary study. J Alzheimers Disease 20, 517-526.

[72] Newberg AB, Wintering N, Waldman MR, Amen D, Khalsa DS, Alavi A (2010) Cerebral blood flow differences between long-term meditators and non-meditators. Conscious Cogn 19, 899-905.

[73] Khalsa DS (2001) Alzheimer's disease. In Integrative Medicine, Rakel D ed, Elsevier Saunders, Philadelphia.

[74] Moss AS, Wintering N, Roggenkamp H, Khalsa DS, Waldman M, Monti D, Newberg AB (2012) Effects of an 8 -week meditation program on mood and anxiety in patients with memory loss. J Altern Compl Med 18, 48-53.

[75] Newberg AB, Iversen J (2003) The neural basis of the complex mental task of meditation: Neurotransmitter and neurochemical considerations. Med Hypotheses 61, 282-291.

[76] Streeter CC, Jensen JE, Perlmutter RM, Cabral HJ, Tian H, Terhune DB (2007) Yoga asana sessions increase brain GABA levels: A pilot study. J Altern Compl Med 13, 419-426.

[77] Nash JD, Newberg A (2013) Towards a unifying taxonomy and definition for meditation. Front Psychol 4, 806.

[78] Scheff SW, Neftner JH, Nelson PT (2014) Is synaptic loss a unique hallmark of Alzheimer's disease? Biochem Pharmacol 88, 517-528.

[79] Scheff SW, Price DA (2003) Synaptic pathology in Alzheimer's disease: A review of ultra structured studies. Neurobiol Aging 24, 1029-1046.

[80] Khalsa DS, Amen D, Hanks C, Money N, Newberg AN (2009) Cerebral blood flow changes during chanting meditation. $\mathrm{Nucl}$ Med Commun 30, 1-6.

[81] Kljajevic V, Grothe MJ, Ewers M, Teipel S (2014) Alzheimer's disease neuroimaging initiative. Distinct pattern of hypometabolism and atrophy in preclinical and predementia Alzheimer's disease. Neurobiol Aging 35, 1973-1981.

[82] Leech R, Sharp DJ (2013) The role of the posterior cingulate cortex in cognition and disease. Brain 137, 12-32.

[83] Harrison TM, Weintraub S, Mesulama MM, Rogalski E (2012) Superior memory and higher cortical volumes in unusually successful cognitive aging. J Int Neuropsychol Soc 18, 1081-1085.

[84] Luders E, Cherbuin N, Kurth F (2015) Forever Young(er): Potential age-defying effects of long-term meditation on gray matter atrophy. Front Psychol 5, 1551.

[85] Black DS, Cole SW, Irwin MR, Breen E, St. Cyr NM, Nazarian N, Khalsa DS, Lavretsky H (2013) Yogic meditation reverses NF-kB and IRF-related transcriptome dynamics in leukocytes of family dementia caregivers in a randomized controlled trial. Psychoneuroendocrinology $\mathbf{3 8}$ 348-355.

[86] Pomykala KL, Silverman DHS, Geist CL, Voege P, Siddarth P, Nazarian N, Cyr St, Khalsa NM, Lavretsky DS, H (2012) A pilot study of the effects of meditation on regional brain metabolism in distressed dementia caregivers. Aging Health 8, 509-516.

[87] Devore EE, Grodstein F, Duffy JF, Stampfer MJ, Czeisler CA, Schernhammer ES (2014) Sleep duration in midlife and later life in relation to cognition. J Am Geriatr Soc 62 , 1073-1081.

[88] Ryff CD, Singer BH, Dienberg Love G (2004) Positive health: Connecting well-being with biology. Phil Trans $R$ Soc Lond B 359, 1383-1394.

[89] Holt-Lunstad J, Smith TB, Layton JB (2010) Social relationships and mortality risk: A meta-analytic review. PLoS Med 7, e1000316.

[90] Boyle PA, Buchman AS, Wilson RS, Barnes LL, Bennett DA (2010) Effect of a purpose in life on incident Alzheimer disease and mild cognitive impairment in community-dwelling older persons. Arch Gen Psychiatry 67, 304-310.

[91] Chen ST, Siddarrth P, Saito NY, Rueda F, Haight T, Ercoli LM, Miller KJ, Lavretsky H, Barrio JR, Bookheimer SY, Small GW, Merrill DA (2014) Psychological well-being and regional brain amyloid and tau in mild cognitive impairment. Am J Geriatr Psychiatry 22, 362-369.

[92] Kaufman Y, Anaki D, Binns M, Freedman M (2007) Spirituality, religious practice may slow progression of Alzheimer's disease. Neurology 68, 1509-1514.

[93] Newberg AB (2014) The neuroscientific study of spiritual practices. Jefferson Myrna Brind Center of Integrative Faculty Papers, http://jdc.jefferson.edu/jmbcimfp/14, Paper 14.

[94] Solomon A, Mangialasche F, Richard E, Andrieu S, Bennett DA, Breteler M, Fratiglioni L, Hooshmand B, Khachaturian AS, Schneider LS, Skoog I, Kivipelto M (2014) Advances in the prevention of Alzheimer's disease and dementia. J Intern Med 275, 229-250. 